Cite as: Bruni-Celli, J. F., \& González, R. A. (2013). Meanings for case protagonists of the informing process occurring during case production and discussion: A phenomenological analysis. Informing Science: the International Journal of an Emerging Transdiscipline, 16, 229-246. Retrieved from

http://www.inform.nu/Articles/Vol16/ISJv16p229-246BruniCS04.pdf

SPECIAL SERIES: THE ROLE OF CASE STUDIES IN INFORMING SYSTEMS

\title{
Meanings for Case Protagonists of the Informing Process Occurring During Case Production and Discussion: A Phenomenological Analysis
}

\author{
Josefina F. Bruni-Celli and Rosa Amelia González \\ Instituto de Estudios Superiores de Administración, \\ Caracas, Venezuela
}

\author{
jbruni@iesa.edu.ve rosa.gonzalez@iesa.edu.ve
}

\section{Executive Summary}

This study is concerned with how the protagonists of case studies - carried out by researchers of business schools with commitment to the case method - experience the informing process occurring during case production and discussion. The focus is both on how protagonists personally experience this informing process as well as on how protagonists interpret its impact on their relation with the larger social system. This was explored through in-depth interviews with two managers who had been co-protagonists in a case study produced by a well-known Latin American business school in 2004. A descriptive phenomenological method was used for data analysis. Results show that for protagonists, the informing experience was more emotional than intellectual, more significant for its symbolic meaning than its rational content; they also show that in the lived experience of the protagonists, the informing process increased their legitimacy and authority in the face of other stakeholders located in their relevant field of action. Finally, in the interpretation of the researchers, the protagonists related the informing flows from the case production and discussion to the evolution of their own practice.

Keywords: case method, informing institutions, phenomenology, information systems, business education, informing science, business schools.

\section{Introduction}

Gill (2011), who defines an informing institution as "any organization whose principal purpose revolves around informing," indicates that there are two reasons why the case-method is a powerful means for informing business practice and thus for enhancing the role of business schools as

Material published as part of this publication, either on-line or in print, is copyrighted by the Informing Science Institute. Permission to make digital or paper copy of part or all of these works for personal or classroom use is granted without fee provided that the copies are not made or distributed for profit or commercial advantage AND that copies 1) bear this notice in full and 2) give the full citation on the first page. It is permissible to abstract these works so long as credit is given. To copy in all other cases or to republish or to post on a server or to redistribute to lists requires specific permission and payment of a fee. Contact Publisher@InformingScience.org to request redistribution permission. informing institutions. In the first place, there is fit between case-method research and the complex systems in which business practice takes place. Second, the case-method is a powerful tool for communicating research results. With respect to the latter, Gill points out that the case method serves the effective diffusion of research findings through the relevant practice community because it brings researchers and practitioners 
together in a network of relations in which both are simultaneously "informers" and "clients." More generally, Gill argues that a strong commitment to the case method leads to the formation of an effective (and prosperous) "academic informing system," featuring various two-way informing pathways between practitioners and researchers.

Now, some issues associated with the informing aspects of case method research have been explored more than others. Gill has considered the challenges and benefits - for academic informing systems - of case-based publications and discussions from an Informing Science perspective (Gill, 2010, 2011). He has also looked into the effects of interpersonal relations that are built between researchers and practitioners during case method research, indicating that these interpersonal relations strengthen the diffusion of ideas throughout the academic informing system. Less is known about how, and what kind of, informing occurs in specific pathways of the informing system with the use of the case-method, or about the impact that these specific pathways may have on the larger system. In this paper we explore the features of one such lesser known pathway: the informing that occurs in the direction of a particular practitioner, the case protagonist, in the process of case production and discussion. As we are also interested in knowing about how this particular pathway relates to the informing system at large, in this study we also explore the impact of this informing pathway in the larger system.

A phenomenological approach was chosen to study the pathway and its impacts. The choice is founded on the idea that the perspective of the case protagonist is key to understanding both the informing that occurs in our pathway of interest and its impact in the larger system. Stated from a phenomenological approach, the purpose of the present research is to understand the experience lived by the case protagonists during the informing process that occurs in the context of case production and discussion and to understand the essential structure of the impact of this informing process from the perspective of the protagonist.

\section{The Informing Science Framework}

This paper takes on the informing science perspective used by Gill (2011) in his study of informing with the case method. Cohen (2009) defines the Informing Science transdiscipline as the fields that "provide their clientele with information in a form, format, and schedule that maximizes its effectiveness." Concerns of the discipline are on problems of communication on three levels: technical (accuracy in relaying information), semantic (correctness in conveying meaning), and effectiveness (received meaning affects behavior). Accordingly, the discipline in large part seeks to understand the "fragilities" of informers, channels, and clients. Note from the above that the discipline as defined by Cohen (2009) is normative and applied; also note that the focus of research in this field is on the problems affecting the delivery of information meant to reach the client for a particular purpose.

Is this approach relevant for the purpose of studying the informing that occurs in the direction of case protagonists during case production and discussion? It would be undoubtedly relevant in situations where case researchers are purposely seeking to inform protagonists, such as when researchers are engaging in action research, or in a consulting project with the case protagonist. In the case of consulting, such informing could at times be unilateral, while in action research it would be more collaborative. According to Reason and Bradbury (2001), "Action research is an interactive inquiry process that balances problem solving actions implemented in a collaborative context with data-driven collaborative analysis or research to understand underlying causes enabling future predictions about personal and organizational change". Regardless of the difference between action research and consulting, in both situations, researchers are in one way or another actively trying to inform protagonists (clients); thus they are also naturally interested in knowing how accurately, correctly, or effectively they informed protagonists. But this is not the kind of situation that most commonly accompanies a process of case production. Most frequently, during 
case production researchers are engaged in a process of extracting information from case protagonists. Their purpose not being to inform, but rather to record and analyze a management situation or innovation, to advance in theoretical development with new evidence from a case, or to organize information for teaching and learning purposes. In situations where there is no explicit intention to inform (as happens in a typical process of case production), Informing Science concerns with the accuracy, correctness, or effectiveness with which information was communicated are clearly irrelevant.

Nevertheless, certain aspects of Informing Science framework are useful for the purpose of studying the informing that occurs in the direction of case protagonists during case production. It is true that Cohen's (2009) Informing Science conduit framework (see Figure 1 below) assumes the existence of an informer that is trying to get something across to a client, and it is precisely due to this assumption that the framework focuses on the effectiveness with which this is done, and furthermore looks into how and to what extent this effectiveness is altered by the contextual environment (of the informer, the information transmission and receiving media, and the client) as well as by the needs and fragilities of both informer and client.

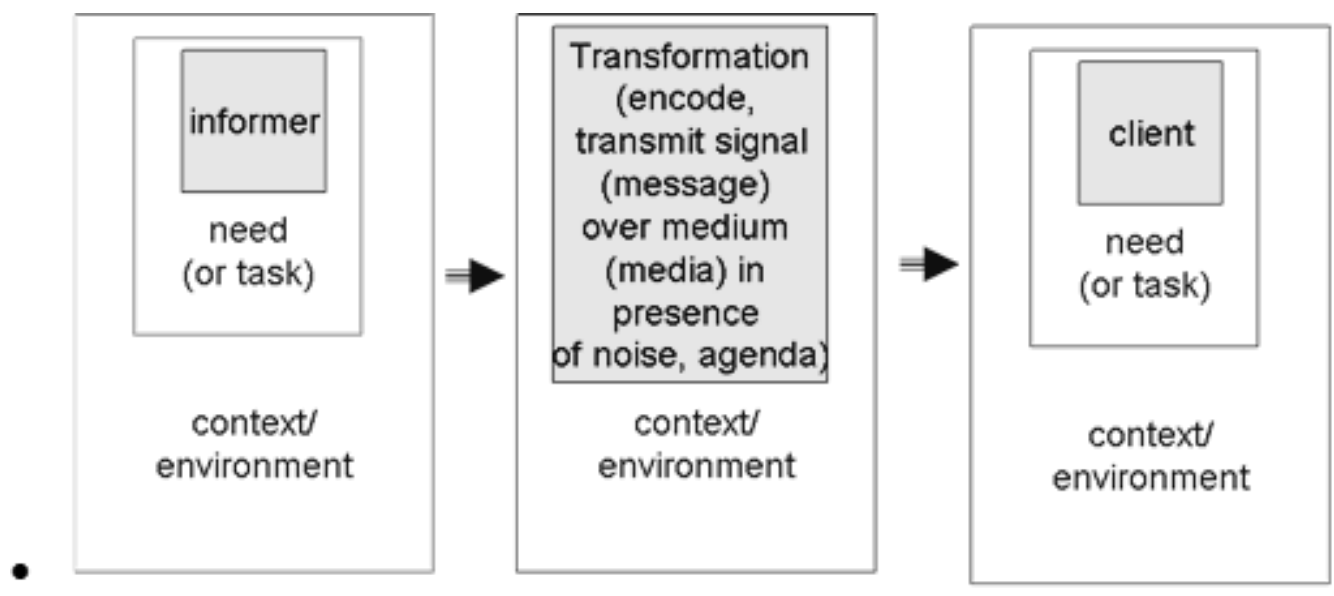

Figure 1: Cohen's (2009) Informing Framework

Now, if we relax that assumption, the framework is still valuable, though the concern will no longer be with effectiveness, but rather with what is in fact communicated. Let us imagine a situation where a person ("source") communicates with another ("receiver") for a particular reason (in our particular study this person would be a researcher communicating with a protagonist for the purpose of extracting data). It is possible that what this person ("source") communicates to the "receiver" will be decoded by the latter in ways that were not specifically intended by the "source", for as is established in the IS conduit framework, the information received by the "receiver" will be largely determined by the needs, tasks, psychology, and contextual environment of the "receiver". The difference between our research and the typical IS use of the conduit framework is that IS seems to be concerned with the level of alignment between the source's specific intentions and the receiver's perception. But if we drop this concern with alignment, the framework can be used simply to identify what is in fact communicated in the pathway from "source" to "receiver" from the perspective of the receiver, and the impact this has on the receiver.

It is possible that what is communicated to case protagonists during case production and discussion has gone underexplored in the Informing Sciences precisely because the concern of the IS with effectiveness has taken the light away from situations where information is not necessarily being sent in a purposeful way. Now, does our focus on a pathway featuring the flow of information in an unintended direction, and our lack of concern with effectiveness or level of alignment between the "sender's" specific intentions and the "receiver's" perception, place this partic- 
ular piece of research out of the field of IS as a discipline? Not necessarily, because we are still concerned with the systems effects of what is in fact communicated. Figure 2 illustrates our concerns at the systems level:

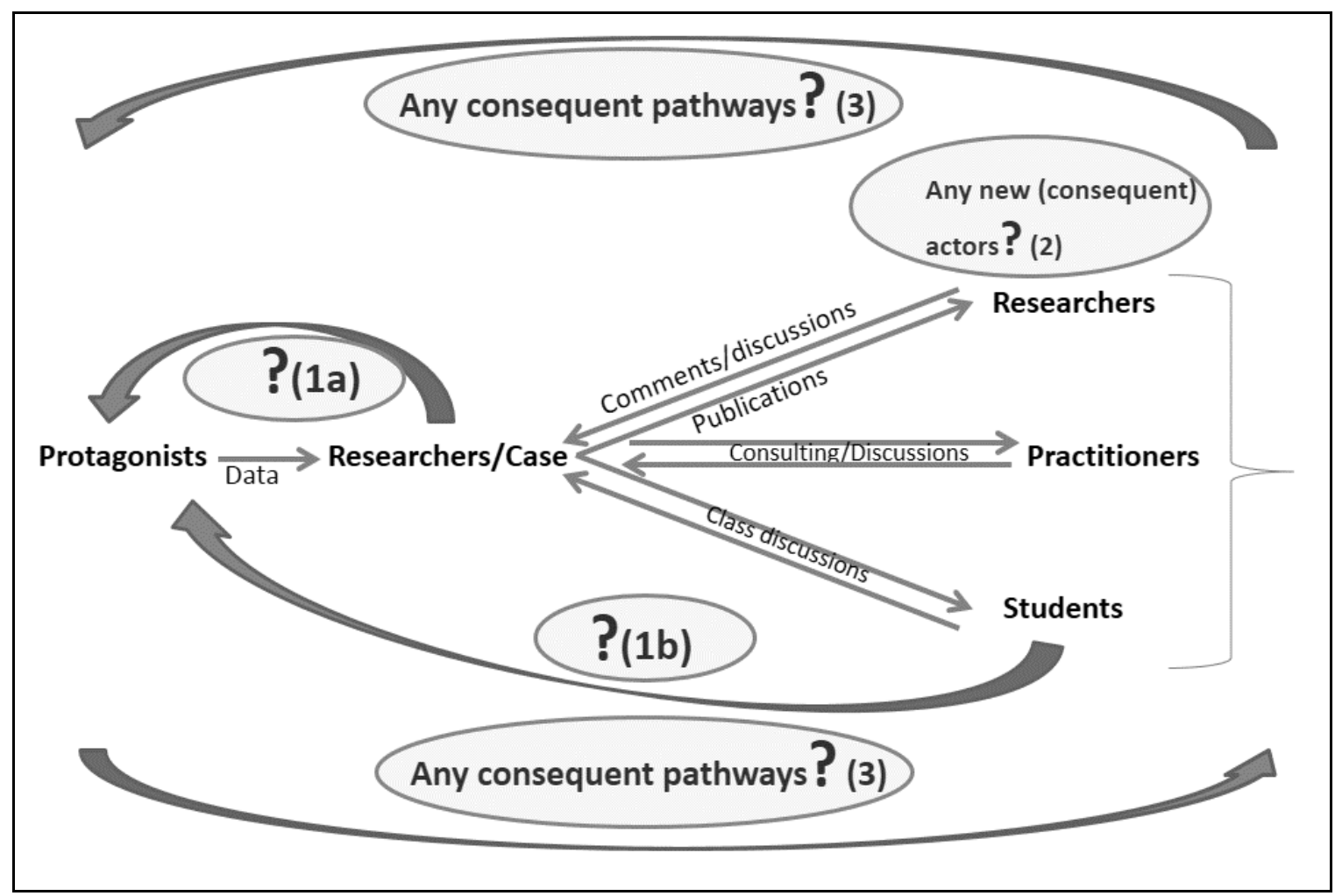

Figure 2: A frame for the analysis of systems effects

Straight arrows show the better-known pathways of information flow. In this study we will be exploring the following less known paths: flows of information from researchers (intended or not) to protagonists during the data collection process, and from students to protagonists during class discussions as indicated by (1) in the figure. But we will also be exploring whether new actors emerge (2) in the information system as a consequence of (1) and, also, whether new paths of information flow emerge between protagonists and other actors (3), also as a consequence of (1). These three areas of inquiry $(1,2$, and 3$)$ correspond to the three levels of analysis proposed by Cohen (1999, 2009, pp. 10-11): "1) the informing instance level, where actual informing takes place; 2) the instance-creation level, where new informing instances are created, and 3) the design level, where general patterns for informing are established."

\section{Case Selection and Features of the Selected Case}

In 2004 a well-known Latin American business school set out to produce a number of cases in the context of a larger research project coordinated by the Social Enterprise Research Network (SEKN), a network composed of Harvard and nine Ibero-American business schools. One of these cases, entitled The Social Initiatives of Ron Santa Teresa, was chosen for the present study for two reasons: 1) the company (Ron Santa Teresa) still exists and has not undergone change of ownership; 2) the teaching case is used frequently in Latin American business schools. Ron Santa Teresa is a 200-year-old family-owned rum company, which produces both sugar-cane and rum in a large estate in central Venezuela. The case is about strategic social investment and features most prominently an innovative and unusual social initiative led by the company's CEO and his security manager. 


\section{Brief Narration of "The Social Initiatives of Ron Santa Teresa"}

The case examines how Alberto C. Vollmer --newly designated chief executive officer and son of the largest shareholder of Ron Santa Teresa (CARST, for its initials in Spanish) -- and his collaborators must reply to threats (land invasions, assaults, other) derived from the poverty of its immediate surroundings in the town of El Consejo, in a highly polarized social and political environment.

Ron Santa Teresa, a sugar cane and rum production company, features a large tract of land located in an area experiencing increasing urbanization pressure from low income population groups. In 2002 a piece of land belonging to the company was invaded by 256 families. During those days President Chávez had been calling for the seizing of the "unproductive" lands of "large landowners." Thus, a few days later, an additional 223 families marched into the lands with the intention of settling them by force. Alberto Vollmer established a dialogue with the leaders of the invasions and offered them a well delimited strip of land with a condition: that all construction should comply with a particular architectural and urban plan. He commissioned the plan and met with the governor of his state to obtain resources for the construction of the invaders' homes.

On February 15, 2003, three members of a gang of juvenile delinquents known as La Placita entered Hacienda Santa Teresa's grounds, assaulting a security guard. When Alberto learned of the incident he asked Security Manager Jimín Pérez to find the youngsters and bring them to the company's offices. Alberto met with two of them and proposed they redeem damages by working for the company without pay for three consecutive months. He said that if they did not want to take his offer, he would simply call the Aragua State Police and report the incident. At the time a list of police forces that summarily executed prisoners had been published by the Venezuelan Human Rights Action Education Program (Provea), with Aragua ranking first.

The youths accepted Alberto's offer after thinking it over during the weekend and brought with them another twenty members of the La Placita gang. Jimín and Alberto were surprised by the response and resolved to go ahead, without giving much thought to what they were about to do. They decided to name the project Alcatraz, after the famous San Francisco prison. Intuitively, Alberto and the managers decided that the youths should work off their three months' time during morning hours, in an area removed from the hacienda. During the afternoons they would be given instruction in values, legal issues, drug abuse, and community work. At the end of each day the youths were to play rugby, a game unknown to any of the youths but which was the Vollmers' favorite sport.

For a somewhat non-structured program, the initial results were unexpected: of the 76 youths admitted to the Alcatraz Project by April 2004, 61 completed three months of training satisfactorily. However, of the 61 graduates, only one had been able to obtain stable employment; the rest had temporary jobs at Hacienda Santa Teresa or other Vollmer family businesses. Even though registered crime data are not considered reliable, Aragua State Police data showed that from 2002 to 2003 the number of crimes reported in El Consejo dropped by 35 per cent.

Despite their apparent success Alberto Vollmer's bold social initiatives faced many challenges. Neither company workers nor his family liked his policy of bringing gang members into the hacienda. The time and energy he was investing in attending his social initiatives was also questioned by board members. Some of the latter believed that there was a risk of backfire in these initiatives. Others thought Alberto was losing his focus and forgetting the company's mission. The teaching case focuses precisely on the dilemmas faced by Alberto in trying to reconcile his social initiatives with his company's mission. 


\section{Interactions between Case Protagonists and Researchers and Students}

Since 2004, protagonists of the case have engaged in a sequence of recurring interactions with business school researchers and students, as well as with other practitioners. The first round of intense interaction occurred between researchers and case protagonists during the case production process, which took place over eight months in the year 2004. In the midst of the case-production process, the two central case protagonists, Alberto Vollmer and Jimín Pérez, presented and discussed their experience with other practitioners in a forum organized by the Latin American business schools. A second round of intense interaction occurred when the two central case protagonists participated with researchers in a Colloquium at Harvard University in 2005, where they also discussed their experience with other practitioners and researchers. Also, over the years, two additional forms of interaction have occurred: 1) case protagonists have interacted with business school students, where the case has been discussed once or twice a year by all MBA students since 2005; and 2) CARST's CEO and case researchers have interacted on various occasions, in both formal and informal settings, and reflected about the case.

In all of the above interactions there was no explicit attempt at informing case protagonists about their practice, at least not in the way one would inform through consulting or action research. Nonetheless, there was reason to believe that information flowed toward the protagonists because when questioned about their actions, a process of reflection and analysis took place. What was unknown, from the beginning of this research project, was what kind of information actually reached protagonists during this process, and what impact this had on them and on the larger system. It is at this point that our inquiry began.

\section{Method}

Two characteristics of this study call for the use of a qualitative method of research: 1) little is known about the phenomenon under study; and 2) researchers are most interested in entering into the world of protagonists, that is, into seeing the world from their perspective (Corbin \& Strauss, 2008; Creswell, 1998). The descriptive phenomenology method developed by Georgi (2012) founded on Husserlian phenomenology - was selected for the purpose of analyzing data and reporting results.

The fundamental assumptions of phenomenology differ from those belonging to the tradition of natural or positive social science. Ontologically, positivism assumes the existence of an objective reality apart from the subject, while phenomenology assumes no such separation; establishing that reality is subjective, socially constructed, and multiple. Phenomenological research can be scientific, in the sense of systematic procedural rigor and inter-subjectivity (Giorgi, 2010), but its epistemology is fundamentally different from that of the tradition of natural sciences/positivism. Positivist epistemology makes the distinction between consciousness and object. In phenomenology, there is no such distinction: "epistemological claims are based solely on how situations were experienced or remembered by the participant" (Giorgi \& Giorgi, 2008, p. 239); and there are no concerns as to whether the object in fact exists or not outside of consciousness.

A phenomenological method was selected for this study for three key reasons. First, as case researchers had not had an explicit intention of informing protagonists in any particular way or with any particular purpose during case production and subsequently, we had no hypotheses with regards to the kind of messages that reached the protagonists, nor about the effects of such messages. Second, phenomenology is particularly appropriate for research on IS because this methodology focuses on meanings (rather that on facts, as one would in positivist research) and their formation in real life contexts, and informing processes are precisely about how recipients give meaning to perceived signals. Phenomenology seeks to discern the essence or structure of the 
lived experience of subjects; and the lived experience of subjects in informing processes is intimately related to how meanings were subjectively constructed. Finally, the situation we are analyzing cannot be empirically observed (in any feasible way) through any other means but the eyes and lived experience of the protagonists themselves.

\section{Data Collection and Processing}

Alberto Vollmer, CEO of Ron Santa Teresa, was contacted by the researchers and the purpose of the study explained to him. After consulting with the other protagonist, chief of security Jimín Pérez, he agreed to participate in the study, and dates were scheduled for in-depth interviews with various protagonists. The two protagonists were interviewed for 1:11 and 1:42 hours, respectively.

Interviews were open-ended. The two participants were asked, "Tell us about your lived experience during interviews with researchers, presentations at the local business school, and case discussions in international forums. What information coming from researchers, students, and practitioners was particularly meaningful to you? What did you feel, what reflections or things came to your mind during your exchanges with researchers, practitioners, and students in the context of data collection and presentations at case discussions and other forums? What were the impacts of your participation in the case study?"

The interviews were recorded and transcribed verbatim by researchers.

\section{Data Analysis}

The method of data analysis used in this study was the descriptive phenomenology method suggested by Giorgi (2012) and Giorgi \& Giorgi (2008). Georgi developed this method for the field of psychology, but indicated that the "method is generic enough to be applied to any human or social science" (Giorgi, 2012, p. 11). According to him, a rigorous and non-reductionist method called descriptive phenomenological method must have the following features (during data analysis):

1) The researcher must assume the correct attitude for the task. First, the researcher must assume the attitude of phenomenological reduction "which means that the researcher must resist from positioning as existing whatever object or state of affairs is present to her" (this is the same as saying that all things are reduced to mere objects of consciousness). Epistemologically, this implies that there is no distinction between consciousness and object, and there is concern as to whether the object in fact exists or not outside of consciousness. In addition, the researcher must refrain "from bringing in non-given past knowledge to help account for whatever she is present to. She concentrates on the given as a phenomenon and everything that is said about the phenomenon is based upon what is given." In the data analysis at hand, this implies that one takes what the protagonists say as given, and refrains from bringing past knowledge (about the protagonists, the company they work in, or their situation) into the analysis. Second, as the analysis is intended to be done from an IS perspective, the researcher must assume an IS "attitude toward the data." Finally, the researcher's "adopted attitude must also include special sensitivity toward the phenomenon being investigated" (Giorgi, 2012, p. 4-5). (Giorgi \& Giorgi, 2008).

2) The following steps should be taken in data analysis (Giorgi, 2012, p. 5-6):

- The researcher reads all the transcriptions to get a holistic feel for the data;

- The researcher re-reads all transcriptions and proceeds to create meaning units by marking the text. Transcriptions are thus marked into constituent parts; 
- The "researcher transforms the data, still basically in the words of the subject [which in our case are the protagonists] into expressions that are more directly revelatory of the psychological import [which in our case is the informing science aspect] of what the subject said." The use of the method of "free imaginative variation is critical for the completion of this step."

- The "more sensitive expressions are then reviewed and with the help of free imaginative variation an essential structure of the experience is written."

- "The essential structure is then used to help clarify and interpret the raw data of the research."

\section{Key Limitation of the Research Design}

The case of Ron Santa Teresa documents a novel set of actions, a set of "successful high-risk decisions" (Gill, 2011, p. 341). As this is a feature that is present in most business case studies (Gill, 2011), the findings of this study are likely to be a valid description of the informing experience of protagonists and its impact in many situations. Nonetheless, it is important to point out that the findings of this study have particular relevance to situations where an innovation occurred. Management innovation refers to the introduction of managerial practices, products, and processes that are new to the firm (Mihalache, 2012). Alberto Vollmer's managerial practices were completely new to the firm in their emphasis on attending social issues, a fact that pulled other company members out of their comfort zone. They were also new to Alberto Vollmer himself, who was permanently tinkering in the unknown terrain of social interventions in his company's social environment. Thus, this study is about how the protagonists of an innovation were informed during case production and discussion, and the impact that this had upon them and upon the system as a whole.

This is a single case study, meaning that there was no saturation in our sampling. This may have limited our capacity to identify the essence of the informing experience and its impacts. Additional future studies applying the same method of analysis to other case protagonists, would contribute to better capture the essential structure of the studied phenomenon.

\section{Results}

Results are presented in two sections covering, in turn, each of the two research questions addressed in this study: 1) what was the lived experience of the case protagonists during the informing process that occurred in the context of case production and discussion? 2) What is the essential structure of the impact of this informing process from the perspective of the protagonist?

\section{Structure of the Informing Experience}

Figure 3 presents the structure of the informing experience, described by protagonists as they lived it through their participation in case production and discussion. During the interviews, protagonists highlighted a number of perceived signals (box on the left of the figure) emanating from researchers, practitioners, or students during case data collection, presentations, or discussions, which were identified as particularly significant by them. Protagonists interpreted these signals (decoded meanings in the middle box), and associated signal-meaning pairs with a variety of feelings, as well as with changes in states of consciousness, attitude, and cognitions (box on the right of the figure). Figure 3 also features a set of contextual conditions that protagonists were explicit in associating with their lived experience. 


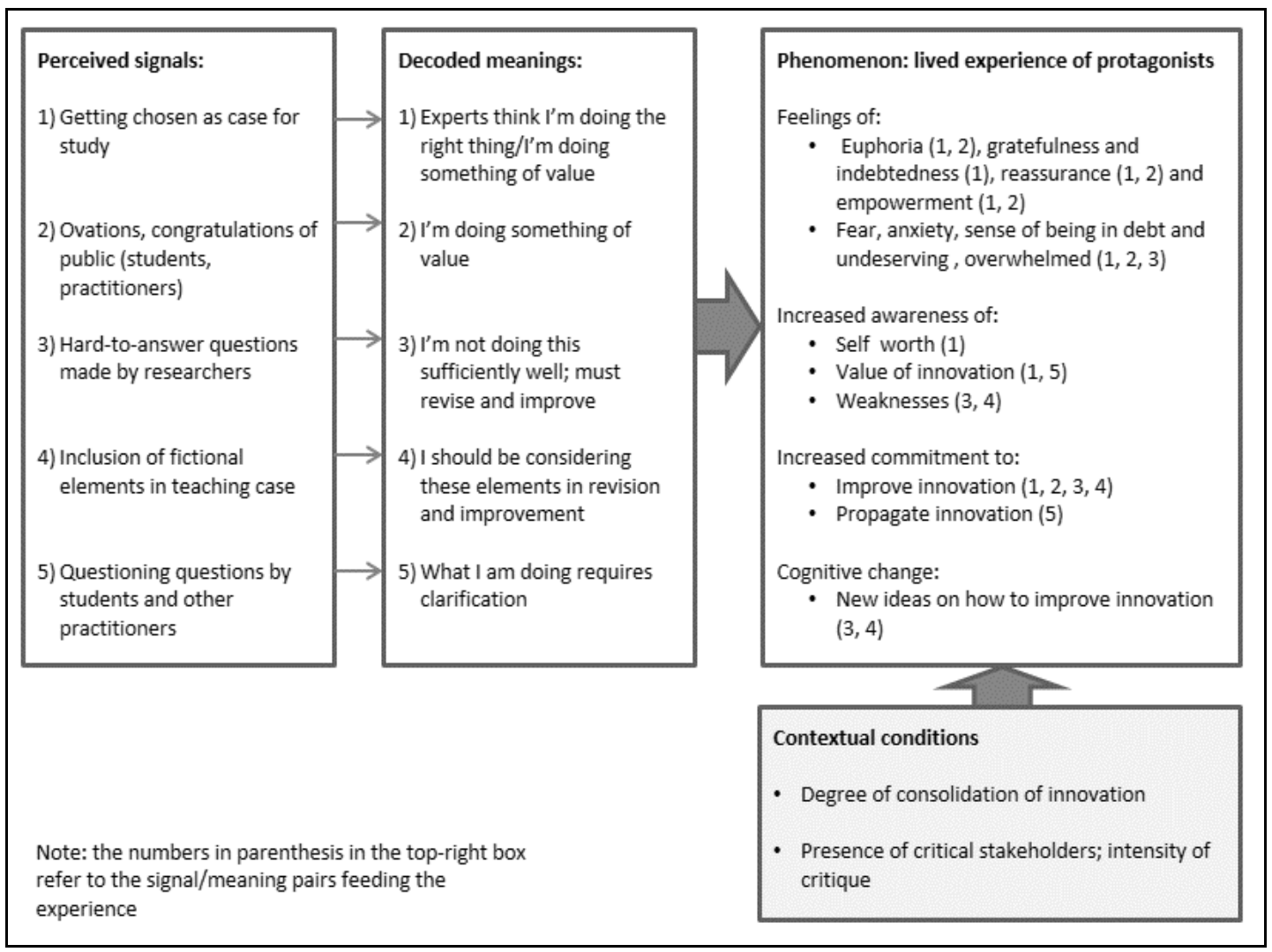

Figure 3: Structure of the protagonists' informing experience

The horizontal process featuring the informing process sequence (signal $\rightarrow$ decoded meaning $\rightarrow$ lived experience) and the lateral effects of the contextual conditions on the lived experience of protagonists are presented in the next two sub-sections in turn.

\section{The Informing Process as Experienced by Protagonists}

The perceived signals are listed in Figure 3 in order of importance for protagonists. The fact of having been asked to participate in a case study was experienced as most significant and as telling of the value of the innovation. For the protagonists, learning about the value of what they were doing came as a revelation:

"I didn't understand why you were interested in our case, you know, I didn't have the vision because we were living the short-term, the day by day problems. It was with you that I began to understand the significance, the long term importance of this." (Jimín)

Feelings of euphoria and gratefulness and of reassurance about being in the "correct path" were also emphasized:

"From a personal and professional point of view it was like a dream come true, a fantasy...I was at a crossroads as to whether what I was doing was the right thing, and I feared I was doing the wrong thing. The fact that Harvard and [a well-known Latin American business school] chose us made me understand the importance, the strategic importance of what we were doing, and that gave me confidence. I now felt I could defy my colleagues." (Jimín).

The last sentence referred to colleagues inside and outside of the company who were critical of the innovation or who doubted it was for the better. 
During the case production period, protagonists were invited to present their innovation in a forum with students and practitioners, which also featured a case discussion session. The applauses and ovations of the public (number 2 in Figure 3), which protagonists had not expected, were also identified as being a highly significant signal and interpreted as meaning that their innovation was of great value. In general, both the ovations and being chosen for the case study were interpreted by the protagonists as qualified authorizations or license for what they were doing, and they felt correspondingly empowered in the face of critical voices in their working environment (recall Jimin's statement about how he felt empowered to defy his colleagues).

The lived experience of getting ovations and having been chosen for the case study also had its darker side. The innovation was still work in progress, protagonists were still doing a lot of troubleshooting, and not all difficulties had been solved --which is why the teaching-case had a dilemma. As a result protagonists felt troubled and in debt, fearful of being undeserving and of having been wrongly chosen: "...it was a feeling of being in debt because here everybody was applauding and I had a lot of unconcluded issues to solve" (Alberto). In reference to being chosen for the case study, Alberto added: "my feeling was that we were gatecrashers" (in Spanish the word for gatecrasher is "colado," which in colloquial language also signifies sham, deception, or counterfeit).

The positive feelings (euphoria, reassurance, gratefulness) and the negative ones (anxiety, not being worthy of the attention) combined to enhance the protagonists' sense of commitment with their innovation and its improvement. In Alberto's words:

"I saw that the game was only starting, that was the feeling...that all of this was very nice, a privilege, but that I couldn't lie to myself, I couldn't be complacent, I had to look into next steps, where to find new resources, knowledge, people [for our innovation]".

The fear of failure and of disappointing were also a key feature of underlying the increased commitment to improving the innovation experienced by Jimín:

"Now we were being watched like lab rats, we had to do things well, keep surprising in the face of expectations... up to now we had surprised without expectations...now that expectations existed we had to look into ways to advance."

"I was fearful of disappointing the researchers that documented the case, the president of [the business school], all the people who were banking on our case."

Note that this commitment was experienced by the protagonists as a commitment with the academic institution, which they did not want to let down.

Two other significant sources of information identified by protagonists were: questions made by researchers during data collection (number 3 in Figure 3), and the inclusion of fictional elements in the teaching case (number 4). The researchers' questions that were most vividly recalled by protagonists were those which were most emotionally stirring due to the lack of answers:

"When he asked me how I was going to satisfy that demand, I felt overwhelmed, because I didn't know. Where was the money going to come from? I had a big question mark" (Alberto).

These hard-to-answer questions were experienced by protagonists as prompts to think about their weaknesses:

"I realized we were extraordinary improvisers... and seeing all of this, I asked myself, how should we go about establishing a structure for social transformation, how will we finance it, where will the money come from, how will we recruit?" (Alberto). 
The reflexive process stemming from hard-to-answer questions led to the analysis of strengths and weaknesses and to development of ideas on how to improve and consolidate the innovation.

As with the hard-to-answer questions, the inclusion of a fictional element in the teaching case was also interpreted by protagonists as something to look into for revision and improvement. To illustrate, in the teaching case researchers included a fictional scene in which Alberto was about to meet with his board to hear out the doubts of board members with regards to his social initiative with young delinquents. Alberto recalls his reaction to this fictional text as follows:

"When I saw that I said to myself, oh boy, I had completely forgotten about the board, I had not been conscious about this. When I took the decision it never occurred to me that I should have consulted the members of the board...you [researchers] invented it but many people in the company had thought this; my family had thought this" (Alberto).

Critical, probing questions by students and practitioners in forums and classrooms were also recalled as significant moments by protagonists, but their interpretation of these questions was very different from questions posed by researchers. In this case, critical questions did not prompt reflection about weaknesses of the innovation and routes for improvement. On the contrary, the way protagonists recalled critical questions by students and practitioners was as reflecting the questioner's lack of knowledge about the situation the protagonists had been confronting, or misunderstandings that required clarification. This difference may have to do with the fact that by the time protagonists were confronted with questions from students and practitioners, they had already engaged in deep reflection, as a consequence of their interaction with researchers, about their strengths, weaknesses, motives, and decisions and had made up their mind with regards to a number of next steps.

In the case of critical questions by students and practitioners, protagonists referred to a learning process as to how to improve answers to frequently asked questions:

"There are questions that always show up in these sessions. Some are hard questions and I haven't always done a good job of answering them. The audience has not liked some of my answers. Today I have some better answers (Alberto)."

Though, as indicated above, hard questions coming from students and practitioners did not lead to reflections about weaknesses of the innovation or about ways to improve it, they did prompt protagonists into analyzing the practical and moral soundness of their initiative, for it was through this reflection that answers to hard questions could be improved. The questioning "led me to knowing my own story a lot better" said Alberto in reference to the pragmatic and ethical dimensions of his decisions in the case. This experience made the protagonists more conscious of the ethical value of their decisions, reinforced their conviction that they were doing the right thing, and heightened their commitment to propagate their innovation.

\section{Contextual Conditions Affecting the Informing Experience}

The bottom right box in Figure 3 shows the contextual conditions that we interpreted as leading to variations in the informing experience of case protagonists. These variations were not observed "empirically" to the extent that this is not a multiple case study in which one would have observed variations between cases (recall that this is a single case study). Instead, we concluded that these contextual conditions were relevant because the protagonists repeatedly related their lived experiences to them. These were the following:

\section{Degree of consolidation of innovation}

Protagonists explicitly associated the low level of consolidation of their innovation with feelings of fear and anxiety in the face of ovations and applauses: feeling overwhelmed when asked ques- 
tions, and feeling undeserving about having been chosen for the case study. They also associated the low level of consolidation of their innovation with feelings of surprise at the interest of researchers in their case and, thus, with unprecedented insights about the value or importance of their innovation.

\section{Presence of critical stakeholders and intensity of their critique}

Protagonists also related this condition to the way in which they lived the informing experience. Their feelings of euphoria, gratefulness and indebtedness, reassurance or empowerment upon being chosen and applauded for their initiative were closely associated with the circumstance of being questioned and even harassed by relevant stakeholders in their immediate working environment, when the case production process began in 2004. An example of how Jimín established this relation is the following:

"My colleagues [law enforcement officers] were telling me that what I was doing, this thing about working pedagogically with delinquents, was good for nothing...they were pressuring me to turn the boys over to them...but when I came into contact with you [referring to the business school researchers] I was able to see the whole of the forest, you gave me the confidence I needed".

\section{Impacts of the Informing Process}

Figure 4 presents the structure of the impacts of the informing process as described by protagonists.

Impact on protagonists

- Legitimation/increased power founded on increased legitimation in working environment

- Personal and professional growth/impact on family

- Increased fame/increased market value

Impact on company/business practice

- Innovation is improved and institutionalized

System effects

- Accelerated diffusion through invitations/media

- New informing pathways with new actors and resources

- Adaptations of innovation for propagation in new contexts (note: also belongs to category of business practice)

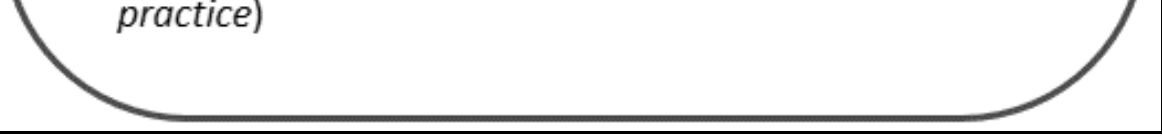

Figure 4: Structure of impact of the informing process 
The informing processes leading to each of these impacts are presented in turn below.

\section{Increased power in the working environment founded on increased legitimation}

Protagonists faced strong opposition to their project from stakeholders located within and outside the firm. The informing process had the effect of legitimizing their initiative in the eyes of these resistant others:

"One of the things I liked the most about participating in the case study was that a third party, a neutral and objective arbiter, with research capacity, had come to document the process...the fact that I had detractors...made the fact that a third party was documenting our case, an enormously satisfactory thing, because now it wasn't just my word against theirs." (Alberto).

"When our project started there was resistance among my colleagues [law enforcement officers], they questioned my reputation...but when we began to participate in the case...they started calling me asking for the magic formula [chuckle]....People began to become interested because we had the backing of important institutions like you and Harvard, it was all like a rocket." (Jimín)

Protagonists viewed the effect of this as an important factor bolstering their capacity to push and consolidate their initiative:

"This [the legitimizing feature of participating in the case study] was of great utility...it generated a platform, a foundation upon which I could continue constructing, strengthening the project...for the fact that we were a case study of [the Latin American business school] and Harvard served us like a lever here, in this community, and this allowed us to continue generating change in the company" (Alberto).

The effect went beyond the defense of the initiative. For Alberto, who was a young manager struggling with an inter-generational transition, participating in the case had the following additional effect:

"Dad was not so credulous about my capacity to take the helm of the ship, and the case was one of the guarantors of that recognition" (Alberto).

Figure 5 expresses in the language and approach of the informing science philosophy the process that according to protagonists led resistant stakeholders to accept and even begin to support the innovation. Having been chosen as a case worthy of study and the public ovations in presentations at the Latin American business school were interpreted by resistant stakeholders as indicative that both experts and the general public thought that protagonists were doing something of value. Protagonists also pointed out that as a result of their presentations they and their innovation began to receive attention from the press, which in turn triggered a flood of invitations (both national and international) to give talks about their innovation. These facts, they said, led to increased support and reduced opposition from previously resisting stakeholders.

Jimín added that after the case study began, Alberto invested in him by sending him abroad to take courses in conflict resolution and negotiation. In Jimín's view, as a consequence of his participation in the case study he became an important role model for his own children: "The fact that my children saw me travelling and giving talks about the case in other countries and at Harvard had a strong impact on them. All my children are in graduate school." 


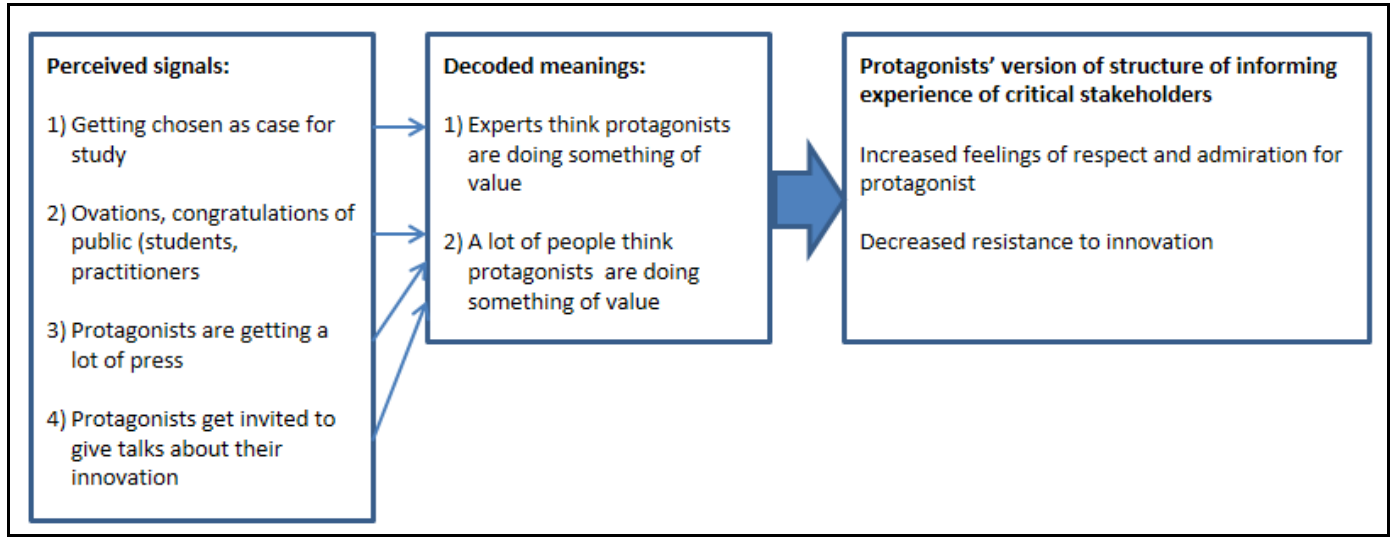

Figure 5: Structure of other stakeholders' informing experience

\section{Accelerated diffusion of innovation through invitations/media}

Recall that protagonists pointed out that as a result of their presentation at the Latin American business school, they and their innovation began to get a lot of press, which in turn triggered a flood of invitations (both national and international) to give talks about their innovation. Protagonists eagerly and enthusiastically attended to all these invitations because they were convinced of their "responsibility" to make their innovation known to other practitioners.

\section{Increased fame/increased market value}

Jimín pointed out that a few months into his participation in the case study he began to be sought out by headhunters. It was something he had never expected, and at first didn't believe it:

"I was sure it was some prank of Alberto's and I said to myself, 'he is such a nag!' So one day, after receiving more e-mails with a particular job offer I said to him 'come on Alberto, that's enough'! And he asked me with surprise, 'but Jimín, what are you talking about?'...And that's when I learned about those human resource companies that are called headhunters, and which compare you in the market. So I told Alberto, 'hey, you've got to stop teaching me, don't teach me anything else!'[chuckles]."

Alberto also pointed out the increased presence of headhunters seeking to recruit Jimín after the case had gained fame, noting that "this generated great fear in me; imagine that they robbed Jimmy from me at that time...it was super complicated."

\section{Innovation is improved and institutionalized}

As indicated above, the legitimizing effect of participating in the case study enabled the protagonists' efforts to improve their innovation and institutionalize it in the company. But what drove the commitment to improving and institutionalizing was rather the questioning by the researchers, combined with the uneasiness of the protagonists with their public recognition. In Alberto's words:

"Participating in the case study had helped me know my story better. And being part of a case study was like a pebble in the shoe that kept reminding us... for it was clear to us that if we didn't do this and that, if we didn't move forward, we would soon only be telling a story about a pretty thing that had happened to us in the past. Now it was a question of looking at ourselves bluntly, of recognizing our good moves and our mistakes, and to say to ourselves: okay, what are we supposed to un-learn in order to move forward, what must we dismantle in order to build?" 
Both protagonists pointed out that this reflexive process led to improving the innovation and that it was collective, involving the two of them as well as new managers specifically recruited for the purpose of helping consolidate the innovation.

To institutionalize the innovation in the company, Alberto also set out to develop channels of communication with other workers: "Through these, Alberto explained to them what we had done... of course they were still fearful of working side-by-side with delinquents, but less so now that they were participating and involved" (Jimín).

\section{New informing pathways with new actors and resources}

Alberto mentioned that both word of mouth and press coverage about the case brought new actors into the system. Most of these were development banks, international cooperation units, or international NGOs. These new actors brought fresh resources for financing the program with delinquents, but above all, they offered advice. The new information coming from these new actors was principally focused on issues of sustainability, replicability, and the "scalability" of the innovation and its impact.

\section{Adaptations of innovation for propagation in new contexts}

The protagonists reported that after participating in the case study, they began documenting their educational program with delinquents in search of ways to improve and package it for replication. They proudly reported that today (December 2012) they are in the process of piloting "Alcatraz 2.0", a more replicable version of this first "improvised" initiative. As Jimín commented to the researchers:

"You were key in opening Alberto's appetite for documenting. If you hadn't appeared, Alberto would probably not have given Alcatraz its academic importance or significance. That is why I say that you were a magic ingredient in what we were experiencing and doing...in developing our strategy of educating [a delinquent]."

\section{Discussion and Conclusions}

\section{Elaboration of Results: The Nature of the Informing Experience}

Contrary to what an academic researcher would think or expect, from the point of view of the protagonists the essence of the informing experience (during case production and discussion) was not so much about receiving new substantive data, but rather about confirming, legitimizing, and empowering. To that extent the experience was more emotional than rational or academic. Accordingly, the signals referred to as being most significant in the informing process weren't the ones featuring recommendations from researchers or other practitioners (not even ones in the form of reflexive questions), but rather the fact of having been chosen for a case study and being applauded during presentations of their innovation. These signals served to clear self-doubts and amplify the protagonists' feeling that they were doing the right thing.

\section{Contextual Factors and Variations in the Informing Experience}

The experience was predominantly emotional, though in a complex way, as it included a mix of high and dark sensations. Two contextual components seem to have had an important influence on the intensity and direction of the emotionality in the experience: 1) the degree of consolidation of the innovation; and 2) the presence of critical stakeholders and the intensity of their critique. Though more data from a varied group of protagonist would be required to confirm the influence of these two contextual conditions in variations of the experience, the results of this study point to the following two propositions: 
Proposition 1: If the innovation is consolidated (rather than in the process of being developed and featuring troubleshooting), the protagonists are less likely to experience fear, anxiety, or a sense of being overwhelmed and in debt. Also, if the innovation is consolidated, having been chosen for the case study is less likely to lead to increased awareness of self-worth and value of the innovation.

Proposition 2: To the extent that protagonists do not face stakeholders critical to what they are doing, having been chosen for the case study will not lead to strong feelings of euphoria, gratefulness and indebtedness, reassurance or empowerment.

\section{The System's Effects on the Informing Process}

The informing experience of protagonists and the impacts of the informing process can be reconsidered with the use of the framework presented in Figure 2. Pathways 1a and $1 \mathrm{~b}$ in Figure 2 are reported in our results in the form of the structure of the protagonists' informing experience. In the two immediately preceding sub-sections we highlighted two key features of this informing experience. Here we will only add that (1b) was not a very significant pathway of information flow from the point of view of protagonists, who indicated that student questions were predictable and always the same.

The pathways labeled 1a and 1b comprise what Cohen $(1999,2009)$ calls the "instance level", where the actual informing took place during case production and discussion. New informing instances emerged in the system as a result of protagonist participation in the case study. In our particular case, one relevant group of new informing instances was comprised of development banks, international NGOs, and international cooperation units. These instances approached the protagonist after being informed about the case through mass media, in presentations at the Latin American business school, through consequent word of mouth, and in presentations in other institutions. The latter also comprised a group of new instances, whose number multiplied as information about the existence of the case spread through the system (through a spiral of mass media, presentations and word-of-mouth). In general, the process of formation of new instances-which corresponds to the "instance creation" level of analysis listed by Cohen $(1999,2009)$ - was very dynamic in the case of the Alcatraz project in Ron Santa Teresa. New venues for presentations gave momentum to the dissemination process. On the other hand, development banks, international NGOs, and other new actors brought a second wave of information into the system .Unlike the data collection process, this second wave was purposefully formulated for transmission to the protagonists through structured consultation and advice.

Though not the product of rational design, a new informing system (Cohen's third, or design level, where general patterns for informing are established) did emerge organically, over time, from the original interaction between the protagonists and the academic institution. It is important to point out, that in this particular case, the Latin American business school was not central in the new informing system, at least not from the perspective of protagonists. The new actors, including governmental institutions such as those responsible for criminal justice, played a more important informing role from the point of view of protagonists in the system which emerged over time the Latin American business school continued to inform in the context of the classroom. But contrary to what was indicated by Gill (2011), the interpersonal relations (which did develop) between researchers and the protagonists did not lead, in this particular case, to consulting or other forms of informing collaborations with the protagonists.

As final note, it is also important to point out that contrary to Gill's (2011, p. 340) findings, protagonists never mentioned having developed relations with students or other practitioners in the context of case discussions. 


\section{Impact on Business Practice}

The most immediate effect of the informing process during case production was on the legitimacy and authority of the protagonists in the face of other stakeholders located in the protagonists' relevant field of action. Legitimation was a prerequisite to further efforts in improving business practice. As suggested in the previous section on system formation, business practice was affected in the mid-term effect by the involvement of new informing actors (development banks, international NGOs, and international cooperation units, and even governmental institutions), in addition to the original informing institution, the Latin American business school.

\section{References}

Cohen, E. B. (1999). Reconceptualizing information systems as a field of the transdiscipline informing science: From ugly duckling to swan. Journal of Computing and Information Technology, 7(3), 213-219.

Cohen, E. B. (2009). A philosophy of informing science. Informing Science: the International Journal of an Emerging Transdiscipline, 12, 1-15. Retrieved from http://www.inform.nu/Articles/Vol12/ISJv12p001-015Cohen399.pdf

Corbin, J., \& Strauss, A. (2008). Basics of qualitative research: Techniques and procedures for developing grounded theory. Thousand Oaks: Sage Publications.

Creswell, J. W. (1998). Qualitative inquiry and research design: Choosing among five traditions. Thousand Oaks: Sage Publications.

Gill, T. G. (2010). Informing business: Research and education on a rugged landscape. Santa Rosa, CA: Informing Science Press.

Gill, T. G. (2011). Informing with the case method. Santa Rosa, CA: Informing Science Press.

Giorgi, A. (2010). Phenomenology and the practice of science. Existential Analysis, 21(1), 3-22.

Giorgi, A. (2012). The descriptive phenomenological psychological method. Journal of Phenomenological Psychology, 43, 3-12.

Giorgi, A., \& Giorgi, B. (2008). Phenomenology. In J. A. Smith (Ed.), Qualitative psychology: A practical guide to research methods (2nd ed., pp. 26-52). London: Sage Publications Ltd.

Mihalache, O. R. (2012, January). TMT processes as antecedents of management innovation: The moderating role of absorptive capacity. In Academy of Management Proceedings (Vol. 2012, No. 1, pp. 1-1). Academy of Management.

Reason, P., \& Bradbury, H. (2001). Introduction: Inquiry and participation in search of a world worthy of human aspiration. In P. Reason \& H. Bradbury (Eds.), Handbook of action research: Participative inquiry and practice. Trowbridge, Wiltshire: Cromwell Press Limited. 


\section{Biographies}

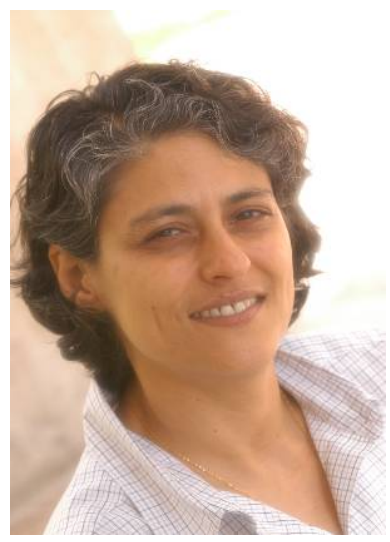

Josefina Bruni-Celli is Ph.D Public Administration, New York University (2001); MBA IESA (1988); B.A, Political Science Yale University (1983). As a professor in the Centre for Public Policy in Venezuela's Instituto de Estudios Superiores de Administración (IESA), Dr. Bruni Celli teaches various classes in business and public policy including Tools for Information Analysis, Evaluation and Design of Public Policy, Enterprise State and Society, Ethics and Corporate Social Responsibility. Together with other professors of IESA, Dr. Bruni Celli is an active member of Social Enterprise Knowledge Network (SEKN). The majority of her research on the social responsibility of business has been issued outside of Venezuela by major publishers, including Harvard Business School.

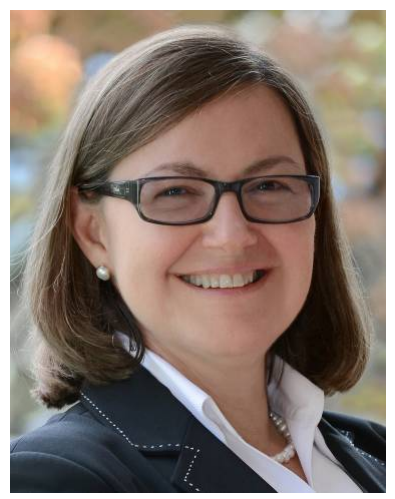

Rosa Amelia González de Pacheco is Ph.D Political Science, Universidad Simón Bolívar (2002); MBA with concentration in Public Service and Public Enterprises, IESA (1988); Urban Planner, Universidad Simón Bolívar (1981). Professor González is the Academic Dean of Venezuela's Instituto de Estudios Superiores de Administración (IESA). As professor in the Centre for Public Policy of IESA, she teaches Enterprise, State and Society in the MBA and Public Management in the MPA. Professor González is a member of Social Enterprise Knowledge Network (SEKN) and coordinates the project in Venezuela. Her research on Corporate Social Responsibility and Social Enterprise has been published outside Venezuela in articles, books and teaching cases. 